\title{
Franken, Clemens. La literatura debe estremecer el corazón: la forma de pensar y la imagen del poeta, del mundo y del hombre en Gertrud von le Fort. Buenos Aires: Ágape Libros, 2019. Páginas: 290. ISBN: 978-987-640-542-3
}

\section{Roberto Onell H.*}

El título de este libro es una afirmación tan anhelante como esperanzada -la literatura debe estremecer el corazón- y que se despliega en cinco apartados que revisaré no sin antes hacer el siguiente énfasis, que me permito derivar del título. Y es que al menos uno de los deseos que se agazapan en ese enunciado es el deseo de encontrar un sentido a la existencia humana. Que la literatura pueda estremecer el corazón supone, por parte de cada uno de sus partícipes, algo más que una relación laboral o estudiantil con las letras. Supone, también, un corazón que acaso se deja estremecer, un corazón que se amasa de preguntas: de cómo, de dónde, de cuándo, de quién, de para qué, de para quién, de con quién... No me refiero, por cierto, al 'corazón' bastardeado por los mercaderes y por los malos trovadores, sino al corazón que se nos ha lamentado sediento, hambriento y anhelante en la propia vida y, también, el corazón que nos ha sido enseñado por los grandes maestros de la humanidad. El corazón, en definitiva, como habitante del lenguaje, morador de las palabras. El corazón dignificado por su creador y por su esperanza.

Porque, a la pregunta por el sentido de la existencia -el sentido del sufrimiento, del trabajo, del morir, del no morir-todos respondemos de no tan diversas maneras. Sin hablar, la vida de cada cual hace un dibujo, puede hacer un dibujo, legible, atendible, borroso, prístino a veces. Pero hay ocasiones en que podemos responder esa pregunta con palabras, con algún enunciado heredado en la inercia generacional, o con alguna sentencia dictada por el desengaño, e incluso con alguna definición institucional, o ciertas citas siempre oportunas. Ahora bien, cuando la pregunta por el sentido se agudiza, cuando se radicaliza, cuando empieza 
a doler de tan urgente, entonces la palabra queda en evidencia en su miseria, quebradiza en sus certezas, interferida de silencio, obstruida. $\mathrm{O}$ quizá pronta a manar otra vez como poesía.

El libro de Clemens Franken es un estudio totalizador de la obra de Gertrud von le Fort -escritora alemana nacida en 1876 y fallecida en 1971destinado a caracterizar y valorar las directrices estéticas e intelectuales acerca del poeta, del mundo y del ser humano, que nutren la escritura de la autora, principalmente sus novelas Das Schweißtuch der Veronika (El velo de Verónica, de 1928), Die Letzte am Schafott (La última en el cadalso, de 1932) y Der Kranz der Engel (La corona de los ángeles, de 1946). El primer capítulo, "La forma de pensar poética de Gertrud von le Fort" (25-69), se extiende acerca del respeto profundo hacia todo lo creado, como principal actitud existencial y literaria de la escritora. Con base en algunos hitos biográficos e inmediatamente literarios, Franken nos va mostrando los diversos alcances estéticos e intelectuales de ese peculiar respeto ante el mundo, donde el asombro y la percepción amorosa tienen tal preponderancia, que acaban por dar nuevo valor a la intuición y al símbolo como formas de conocimiento. Porque, junto a la autora, Franken reivindica todo aquello como forma de pensar y de conocer, esto es, de crecimiento en la comprensión del mundo. La lección fenomenológica de Edmund Husserl y de la empatía en el pensamiento de Max Scheler, entre otros aportes, cobran aquí especial relevancia.

En el segundo capítulo, "La imagen del poeta" (71-83), el autor sintetiza con trazos bien precisos el perfil del creador literario según Le Fort. En formulaciones que podrían haber ganado, por ejemplo, el acuerdo de Oscar Wilde, la escritora puntualiza que la literatura "no pretende un reconocimiento moral, sino un corazón estremecido" (76), y no porque la ficción literaria deba renunciar a la moralidad, sino más bien porque debe internarse en todos los vericuetos posibles del alma humana y de ese modo lograr la total empatía de la que hablaba su amigo Scheler. Quizá porque la misma Le Fort sabía, buena lectora estremecida, que la literatura edificante -política, religiosa, moral- se trunca y acaba por caer, inmovilizada, reducida a eslogan. Por ello, dirá también que la literatura no es "expresión de la personalidad, sino entrega de la personalidad" (76) y, en tanto que forma de entrega, es también "una forma de amar" (77). Y para más señas, revisemos esto: "El verdadero poeta sabe siempre que el objeto crea junto con él, sabe de la penetración misteriosa del objeto en él, de las comunicaciones a menudo casi milagrosas que recibe. 
Que no se piense que solo el poeta ama al objeto: el objeto lo ama a él" (81). Si Franken ha anotado respeto, asombro, intuición, la percepción amorosa se desata aquí con una pluralidad de manifestaciones que suponen -me atrevo a decirlo así- una conyugalidad de inmanencia y trascendencia. No es de extrañar, entonces, que Clemens Franken cifre el arte poética de Le Fort en términos de transfiguración, redención y anunciación, conceptos que acercan esta imagen del poeta -postulo- a la que Dostoievski plasma en Ivan Petrovich, Vania, el escritor y narrador de la novela Humillados y ofendidos, de 1861. El escritor es aquel que, primero, escucha, contempla, se afecta con el mundo, y sólo después ofrece una figura alterna, una trans-figura de él, con miras a una imagen acaso más genuina que acompañe el caminar del ser humano en este mundo.

El mundo es el escenario de una historia donde anida lo sagrado como sentido último de su acontecer. Por eso, "El mundo como misterio en Gertrud von le Fort" (85-101) es el nombre del tercer capítulo, perfectamente consistente con el anterior, y donde Clemens Franken aborda el problema del mal y la realidad del amor divino como dos auténticos misterios según el pensamiento de la escritora. Misterios no en el sentido negativo al que nos acostumbró el pensamiento iluminista, como aquello que no es posible conocer, sino en el sentido positivo de la sabiduría judeo-cristiana: como aquello que nunca terminamos de conocer, porque es inagotable en su verdad. En palabras de Franken: "el último piso de la casa del ser, que forma la base de todo lo que existe, es el amor inagotable de Dios" (97). Es un mundo y un universo, tal como lo cantara Dante en su Comedia, sostenido y movilizado por el amor de Dios.

Ahora bien, en cuanto a la acción humana en este mundo, "La imagen del hombre en Gertrud von le Fort" (103-247), el cuarto y más extenso capítulo del libro, aborda algunos tipos humanos de la narrativa lefortiana y se concentra en la figura de Enzio, el protagonista masculino de El velo de Verónica y de La corona de los ángeles. En este afán, Franken encuentra en Nietzsche un poderoso referente en cuanto al vitalismo y a cierto nihilismo del personaje, como también en cuanto a la despiadada crítica al pensamiento cristiano que Enzio encarna. El crítico se toma un valioso tiempo para reseñar y examinar los principales hitos del pensamiento nietzscheano, con importantes lazos tendidos hacia otros pensadores, entre ellos Martin Heidegger y Edith Stein; lazos que, en el “Apéndice” 
(277-289), se amplían a la misma Stein y a Teresa de Ávila. Pero todo el capítulo cuarto es un abanico abierto a cuestiones tan gravitantes como la tensión entre libertad y autoridad, entre individualidad y comunidad en la realidad de la persona, entre el respeto a lo creado y el abuso de poder de cierto utopismo. En su desarrollo, Franken aborda de frente la dura crítica a la Iglesia cristiana y católica en particular que Gertrud von le Fort ficcionaliza en El velo de Verónica, tanto como se empeña en dar el justo relieve que la mujer adopta en el pensamiento lefortiano. Porque, lejos de igualar a las mujeres con ciertas nefastas características del mundo configurado por cierta masculinidad, la escritora consigue ofrecer una genuina alternativa en los caracteres femeninos, cultivados en los valores menos fálicos y muy activos de la intuición, de la acogida, de la ternura, de la compasión, y que no podemos sino entender como alternativa de genuina humanización. Un cierre verdaderamente ejemplar en cuanto a la escucha del autor de las voces en disputa, al seguimiento de la problemática completa, al examen de sus implicancias filosóficas y dramáticas para las vidas que ahí se juegan.

¿Qué es lo que consigue Clemens Franken al fin y al cabo? A mi modesto juicio, por lo menos tres son las conquistas que podemos celebrar y agradecer al autor. Si bien, tal como oportunamente nos anuncia, él atiende a los tres relatos principales de la escritora, creo que, en primer lugar, el autor consigue trazar un mapa temático y conceptual de la completa obra lefortiana, hecha de novelas, cuentos, poemas, ensayos y textos autobiográficos. Pero este libro no se conforma con ser mera cartografía: Clemens Franken nos entrega un mapa verdaderamente estremecido, palpitante, vivo; es decir, valorado, movilizado desde las propias opciones de pensamiento y de vida, tal como lo pondera en el "Prólogo" (13-14) Cecilia Avenatti, integrante de la ALALITE ${ }^{1}$. Se puede coincidir o no coincidir con Franken, aquí o allá en este libro, pero no se puede no pensar con él. Y es este un servicio mayor en el trabajo académico humanista: invitarnos y movernos encarecidamente a pensar, a plantearnos problemas que importan, a dar soluciones al menos en este campo de pruebas que son el lenguaje y la ficción literaria.

En segundo lugar, Franken consigue relevar a Gertrud von le Fort como una pensadora cabal, toda vez que demuestra que la ficción novelística es una modalidad de pensamiento, de enfrentamiento

1 Asociación Latinoamericana de Literatura y Teología (www.alalite.org). 
comprensivo de lo real, una tentativa descifradora y recifradora respecto del mundo, donde la razón se toma de la mano con la intuición, el cálculo con el sentimiento y la argumentación con las imágenes. Un pensamiento donde la dimensión estética de lo creado y del trabajo creador revela sus consecuencias éticas de largo alcance para las relaciones interpersonales y para las relaciones políticas. Gracias a este esfuerzo del autor nos enteramos de que existe no sólo una poética lefortiana, sino también un pensamiento lefortiano en profundidad, una forma lefortiana de pensar, de hacer vivir a los personajes, de desplegar y problematizar la realidad.

Y en tercer lugar, Clemens Franken ha escrito otra página, ha plasmado otra sesión memorable del antiguo diálogo entre literatura y teología. A distancia de cualquier esteticismo o formalismo pretenciosos que buscan clausurar la conversación entre la obra literaria y el mundo, nuestro autor no huye hacia el extremo opuesto, no renuncia a leer la literatura como literatura, es decir, a respetar y seguir él mismo las reglas del juego de toda ficción, para así, y sólo así, quedar a la altura del diálogo con el mundo que la misma obra instaura y anima. Si la teología es una palabra acerca de Dios, de los dioses, de lo divino, entonces la literatura que se aviene a conversar con ella no hace más que recordar su propio origen, refrescar sus propias raíces. Y señalo 'origen' y 'raíces' no sólo en términos cronológicos sino sobre todo de sentido: si Dios es el absolutamente Otro, entonces es el primer y último sostenedor de cualquier palabra que podamos decir, escribir o cantar. El principal garante del sentido que podamos recibir y transmitir. 